\title{
A Comparison of Nonprofit Hospital Charity Care Policies and Community Benefit in Central Ohio to Peer Cities
}

Sarah Clagg ${ }^{1}$; Andy Wapner ${ }^{2}$; Jeff Klingler ${ }^{3}$; Sharon Schweikhart ${ }^{4}$

${ }^{1}$ The Ohio State University Wexner Medical Center, The Ohio State University, Columbus, $\mathrm{OH}$

${ }^{2}$ Central Ohio Hospital Council, Columbus, $\mathrm{OH}$

${ }^{3}$ Center for Public Health Practice, College of Public Health, The Ohio State University, Columbus, OH

${ }^{4}$ College of Public Health, The Ohio State University, Columbus, OH

Corresponding Author: Sarah Clagg, 2835 Fred Taylor Drive, Suite 3000, Columbus, OH 43202, (419) 571-3484, sarah.clagg@osumc.edu

Submitted July 14, 2021 Accepted December 1, 2021 Published January 28, 2022 https://doi.org/10.18061/ojph.v4i2.8438

\begin{abstract}
Background: Nonprofit hospitals in the United States are required to provide community benefits, including charity care, to receive tax exemption from the federal government. Central Ohio's nonprofit hospitals have agreed to the same charity care policies, which may be unique compared to other communities across the county. The aim of this research is to compare the charity care policies of hospitals in Columbus, Ohio, to their peer cities, investigating if hospitals in similar cities have common shared charity care thresholds and to determine if hospitals in peer cities provided similar levels of community benefit.
\end{abstract}

Methods: Tax data from nonprofit hospitals in 21 cities were collected and analyzed using Microsoft Excel (Microsoft Corporation). City community benefit data was summed and averaged using Excel to create a graphical representation of the data.

Results: Only Columbus, Ohio, and Providence, Rhode Island, reported the same charity care thresholds across hospitals. Data demonstrate that Columbus provides less community benefit in dollars to total expenses compared to peer cities; however, this appears to be only true regarding other community benefit excluding charity care. Columbus was near the median among cities examined in regard to percentage of charity care to total community benefit.

Conclusion: Results suggest variability in the amount and type of community benefit nonprofit hospitals provide. Central Ohio hospitals have the same charity care thresholds and spent approximately the same in total community benefit however it is not transparent how these funds are utilized. Current federal regulations do not assess whether the community benefits reported are affecting community health outcomes.

Keywords: Community benefit; Charity care; Tax exemption; Nonprofit hospital

\section{INTRODUCTION}

The purpose of this descriptive research is to investigate Central Ohio hospitals' community benefit compared to their peer cities and to determine if these hospitals are unique in their collaborative efforts to provide charity care. This information is crucial in understanding current community benefit policies and guidelines on how to improve community benefit services to the areas hospi- tals serve. In the $19^{\text {th }}$ century, United States hospitals were established to treat the impoverished, providing shelter while treating their illnesses.1,2 Government played a role in health care delivery not only by operating hospitals but also by creating regulatory and funding mechanisms to provide healthcare access for the elderly and disabled. Medicare and Medicaid were developed in the 1960s as basic insurance programs for Americans who did not have health insurance. These government programs have changed over 
the past 60 years by providing more Americans with affordable health care options. ${ }^{3}$

Currently, the United States government provides incentives to nonprofit hospitals that provide community benefits and charity care with a tax-exemption status making it more desirable for hospitals to provide community and charity care benefits. In 2019, there were approximately 5200 nonfederal general hospitals in the country, according to the American Hospital Association, with nearly 3000 nonprofit and almost 1000 state and local government operated hospitals. ${ }^{4}$ Today, nearly $60 \%$ of hospitals in the United States are nonprofit in which most are tax-exempt because of their status as charitable entities. ${ }^{5}$ A study by John Hopkins found that on average, nonprofit hospitals saved approximately $6 \%$ of total expenses, or about $\$ 11.3$ million per hospital, due to tax exemptions. ${ }^{6}$

In 1956, the United States formalized the tax-exempt status for nonprofit hospitals if they provided charity care within their ability to do so. ${ }^{7}$ Community benefit was first articulated to the American Hospital Association in 1969 by the Internal Revenue Service (IRS), not in an official document but in a letter of opinion. ${ }^{8}$ Initially, most community benefit services were directed at increasing scope of care to seniors and those with complex chronic problems attempting to prevent hospital readmissions. Through the 1980s and 1990s several organizations, like the American College of Healthcare Executives, and various states attempted to create policies including the requirement of community benefit documentation; however, there was no federal enforcement, leaving hospital community benefit vague and undefined. In 2007, the Schedule $\mathrm{H}$ section of the Tax Form 990 was added by the IRS and was required for all nonprofit hospitals to maintain their tax-exempt status. In 2010, following passage of the Patient Protection and Affordable Care Act, the IRS instituted the requirement that all taxexempt hospitals conduct community health needs assessments every 3 years and report it annually on Form 990. The community health needs assessment identifies health needs, targets programs to address these needs, and measures the impact of community benefit activities. Despite efforts from the IRS, state, and other hospital organizations, there are still no quantifiable measures or goals required of nonprofit hospitals in reporting or exhibiting community benefit delivery for federal or most state purposes. There is no requirement for hospitals to demonstrate a direct relationship between the hospital's community benefit activity and the health status of the community in which they serve. ${ }^{8}$

There is a lack in guidance on how to assess the outcomes of the activities being funded as a result of the more recent IRS specifications following The Patient Protection and Affordable Care Act. There have been no proposed logic models for the delivery of community benefit by the IRS and community benefit funds are typically devoted primarily to charity care. This approach spreads community benefits across various minimally regulated programs therefore making it unlikely to promote a change in a community's health status. Results of 1 research report suggested that evidence-based programs and specific measurable outcomes are crucial in maximizing community benefit as well as modifications to the IRS Tax Form 990, Schedule H to assess benefits to the community in which the nonprofit hospital serves. ${ }^{8}$ This would include assessments of community health status and better specifications regarding the allocations of funds outside of charity care. ${ }^{8}$ The same report found that hospital funding of community health activities often leads to increased hospital community collaboration. ${ }^{8}$ Hospital collaboration is crucial because no institution can singlehandedly change the health status of a community due to the complexities of community health needs. ${ }^{8}$

The majority of hospital community benefit funds, nearly $85 \%$, are spent on charity care and uncompensated clinical care, leaving minimal funds for community health activities. ${ }^{8}$ In 2009, a study showed 1800 nonprofit hospitals spent an average of $7.5 \%$ of their reporting expenses on community benefit with a range of spending from $1.1 \%$ to $20.1 \% .^{7}$ Other types of community benefit are not well defined on the IRS Tax Form 990, Schedule H; however, other types of community benefit could include community building and health improvement services, cash/in-kind contributions, health professions education, subsidized health services, community research, and Medicaid shortfall.5,6,9

Regarding community benefit, results of a review of literature indicated that implementation of charity care policies nationally is inconsistent, and there is no mandate on who should be eligible for charity care. ${ }^{10,11}$ Thus, there is no set minimum eligibility criteria for charity care, and the law does not address which specific services should be covered and included in community benefit.10 One of the challenges of evaluating community benefit and charity care is that the IRS has not established desired outcomes or regulations, therefore, it is up to the hospital or health system to determine the levels of charity care and community benefit provided. ${ }^{8}$ In addition, few states dictate community benefit requirements other than reporting, with no responsibility to report community health needs assessments, minimum levels of community benefit, and minimum income eligibility standards for charity care. ${ }^{5}$ This makes the evaluation of community benefit and validation of charity care program establishment difficult to assess, especially when comparing hospital systems.

Much prior research regarding community benefit proposes implementing federal and state policy to determine set outcomes or goals for community benefit for hospitals, $, 8,12$ and in the same articles authors describe the lack of implementation of community benefit and charity care without benefits related to health behaviors, measurable goals, and outcomes. Consequently, without these guidelines it can be inferred that community benefit may not be making a community impact and cannot be evaluated in its effectiveness.

The Central Ohio Hospital Council (COHC) serves as a forum for Central Ohio's community hospitals to collaborate and address 
issues that impact the delivery of health care to central Ohioans. Per the COHC, Central Ohio hospitals are part of the nonprofit hospital community that provide health care for all residents regardless of their ability to pay, and residents can receive the same quality of care from all of Central Ohio's hospitals. The COHC believes that the total expense of charity care in central Ohio is equally distributed across all hospital systems. This research was designed to articulate the levels of community benefit and charity care in Central Ohio and provide fundamental reasoning for a change in community benefit policy based on current guidelines. The aim of this research is to compare the charity care policies of hospitals in Columbus, Ohio, to their peer cities to investigate if hospitals in similar cities have shared charity care thresholds. An additional purpose of this research is to determine if hospitals in peer cities to Columbus, Ohio, provide similar amounts of community benefit.

\section{METHODS}

The COHC collaboration in Columbus, Ohio, includes Mount Carmel Health System, Nationwide Children's Hospital, OhioHealth, and The Ohio State University Wexner Medical Center. These health systems collaborate with each other and other community stakeholders to improve the value, quality, and accessibility of health care in central Ohio. ${ }^{10}$ Central Ohio's nonprofit hospitals have agreed on the same charity care policies, which may be unique compared to other communities across the county. In 2013, the COHC board of directors adopted a uniform charity care standard for all central Ohio hospitals in which was determined that patients earning less than $200 \%$ of the federal poverty level (FPL) are not billed for services, and those under $400 \%$ of the FPL receive a substantial discount for medical services. These hospitals also assist patients in applying for Medicaid, which covers adults earning up to $138 \%$ of the FPL in Ohio. ${ }^{13}$

Since 2007, United States nonprofit hospitals have been required by the IRS to report information regarding their community benefit activities, mostly regarding dollars spent toward community benefit. These hospitals must report their community benefit as part of their annual tax return. ${ }^{14}$ Columbus, Ohio, hospital tax data were compared to its peer cities which peer cities were determined by The Columbus Foundation's Benchmarking Central Ohio report. ${ }^{15}$ See Table 1.

Peer cities' nonprofit hospitals were identified by utilizing the American Hospital Association's 2020 Hospital Guide.4 The data from each city's hospitals were collected via the IRS Tax Form 990,

\section{Table 1. Nonprofit Hospital Systems in Columbus, Ohio, and Peer Cities}

\begin{tabular}{|c|c|}
\hline City and State & Nonprofit Hospital Systems \\
\hline Columbus, Ohio & $\begin{array}{l}\text { Mount Carmel, Nationwide Children's Hospital, OhioHealth, }{ }^{\star} \text { The Ohio State University } \\
\text { Wexner Medical Center }\end{array}$ \\
\hline Charlotte, North Carolina & Novant Health Inc. \\
\hline Cincinnati, Ohio & $\begin{array}{l}\text { Bethesda Hospital Inc., Christ Hospital, Cincinnati Children's Hospital Medical Center, Mercy Health, The } \\
\text { Good Samaritan Hospital of Cincinnati, Ohio }\end{array}$ \\
\hline Cleveland, Ohio & The Cleveland Clinic Foundation, St. Vincent Charity Medical Center \\
\hline Indianapolis, Indiana & $\begin{array}{l}\text { Community Health Network Inc., Indiana University Health Ball Memorial Hospital Inc., Indiana } \\
\text { University Health Blackford Hospital Inc., Indiana University Health Inc., St. Vincent Hospital and Health } \\
\text { Care Center Inc. }\end{array}$ \\
\hline Minneapolis, Minnesota & Allina Health System, Children's Health Care, Fairview Health Services, Hennepin Healthcare System Inc. \\
\hline Nashville, Tennessee & Saint Thomas Midtown Hospital, Saint Thomas West Hospital, Vanderbilt University Medical Center \\
\hline Orlando, Florida & The Nemours Foundation, Orlando Health \\
\hline Pittsburgh, Pennsylvania & $\begin{array}{l}\text { Highmark Health Group, St. Clair Health Corporation, The Children's Home of Pittsburgh, UPMC } \\
\text { Pinnacle Hospitals }\end{array}$ \\
\hline Portland, Oregon & $\begin{array}{l}\text { Legacy Emanuel Hospital and Health Center, Legacy Good Samaritan Hospital and Medical Center, } \\
\text { Portland Adventist Medical Center, Providence Health and Services- Oregon }\end{array}$ \\
\hline Providence, Rhode Island & Rhode Island Hospital, The Miriam Hospital \\
\hline Raleigh, North Carolina & Duke University Health System Inc., Rex Hospital Inc., WakeMed \\
\hline San Antonio, Texas & Christus Santa Rosa Health System \\
\hline San Diego, California & Rady Children's Hospital-San Diego, Scripps Health, Sharp Memorial Hospital \\
\hline
\end{tabular}

${ }^{*}$ The Ohio State University Wexner Medical Center is a government operated hospital; no other government operated hospitals were included in this research 
Schedule H via GuideStar, which is a nonprofit database run by Candid. ${ }^{12}$ GuideStar was used to extract data from the most current tax year, 2018, including Columbus and each peer city hospital's total expenses, the percentage of FPL in factoring eligibility for free and/or discounted care, total charity care benefit, total other community benefit, and the total community benefit provided per hospital. We standardized charity care and total community benefit by dividing the reported expenditure of each hospital by its own operating expenses as reported on Form 990 for the purpose of comparability. Using Microsoft Excel, each city's hospital data was summed and averaged to create a graphical representation of the data. Government hospital systems are not required to report nonprofit data on the Form 990, therefore this information was unable to be obtained from GuideStar. The COHC collects community benefit data from their partner hospitals, so The Ohio State University Wexner Medical Center data were also included to compare Central Ohio's hospital systems' data. In addition, for-profit hospitals are not required to report this information.

\section{RESULTS}

The number of nonprofit hospitals varied between cities from 1 to 17 , which largely correlated to the size of the city. Chicago, Illinois, the largest peer city, has 17 nonprofit hospitals. Columbus, Ohio, has 3 nonprofit hospital systems not including The Ohio State University Wexner Medical Center. Charlotte, North Carolina, San Jose, California, and San Antonio, Texas were the 3 peer cities with only 1 nonprofit hospital. The median number of nonprofit nongovernment hospitals per the 20 cities researched was 3 .

There were varying levels of charity care thresholds throughout the peer cities and hospital systems with the lowest level for free care being $100 \%$ FPL to $300 \%$ FPL at the highest. Subsequently, the lowest percentage of FPL for discounted care was $250 \%$ and the highest was $600 \%$. Columbus, Ohio, and Providence, Rhode
Island, were the only cities, of those researched, with the same charity care thresholds across hospitals. Both of the nonprofit hospitals in Providence reported a 200\% FPL for free care and a $300 \%$ level for discounted care.

Columbus, Ohio, falls near the median in percentage of charity care to total hospitals expenses at $6.27 \%$, with San Diego, California, at the lowest, 1.96\%, and Charlotte, North Carolina, at the highest, $12.96 \%$. Columbus falls directly between its fellow Ohio cities with Cleveland below it, at $6.03 \%$, and Cincinnati above it, at $7.29 \%$. With The Ohio State University Wexner Medical Center factored in, Columbus is in the bottom third due to the high total expenses incurred at the James Cancer Hospital and Solove Research Institute. ${ }^{1}$ See Figure 1.

Columbus, Ohio, falls in the lowest quartile when comparing the total community benefit to total hospital expenses, at $7.57 \%$. Columbus moves ahead of 1 city with the addition of The Ohio State University Wexner Medical Center at $9.31 \%$. The city with the lowest level of charity care to total hospital expense was Milwaukee, Wisconsin, at $4.02 \%$ and the highest was Cleveland, Ohio, at 17.3\%. See Figure 2.

The last comparison was the percentage of charity care to total community benefit. Again Columbus, Ohio, was in the median of this data range at $66.7 \%$. The lowest was Louisville, Kentucky, at $25 \%$, and the highest was Charlotte, North Carolina, at $98.6 \%$. When The Ohio State University Wexner Medical Center was factored in the percentage in Columbus decreased to 50.4\%. Looking at the data, Columbus provides similar levels of charity care to other peer cities like Minneapolis, Nashville, Cleveland, Raleigh, Kansas City, and Cincinnati. However, Columbus provides a lower percentage of community benefit to total expenses than only Milwaukee, Orlando, and Charlotte. Columbus is similar to other cities in comparison to percentage of charity care of total community

\section{\% Charity Care to Total Expenses}

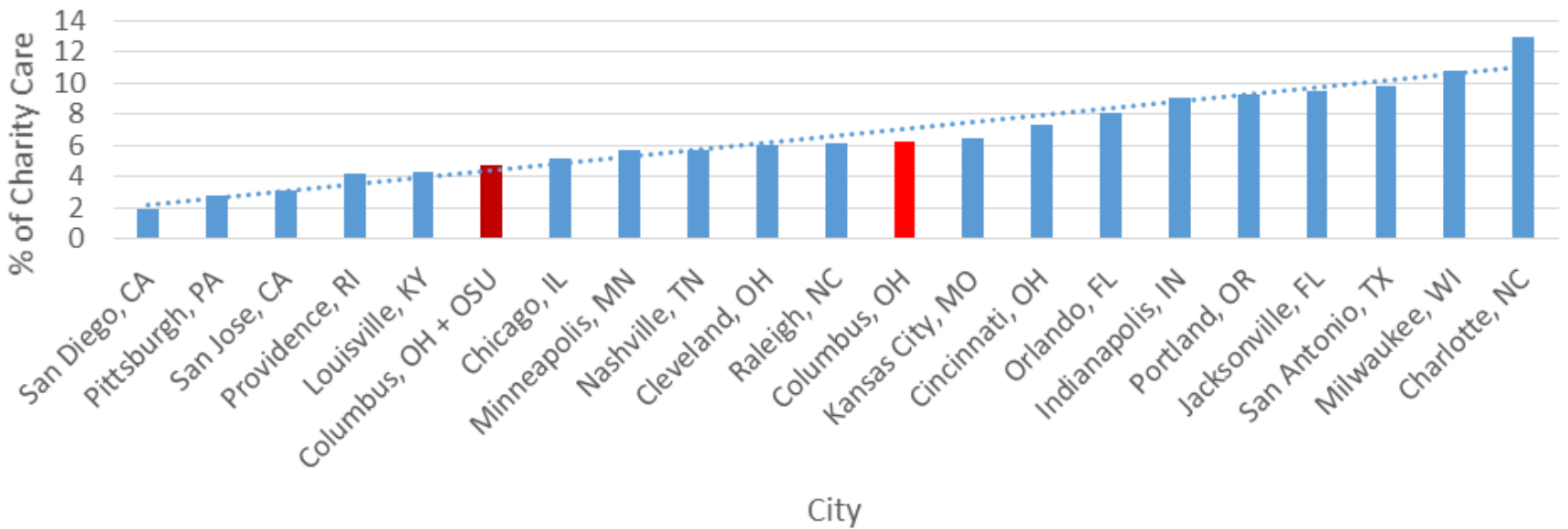

Figure 1. Percentage of Averaged City's Nonprofit Hospital(s) Charity Care to Averaged Total Expenses 


\section{$\%$ Total Community Benefit to Total Expenses}

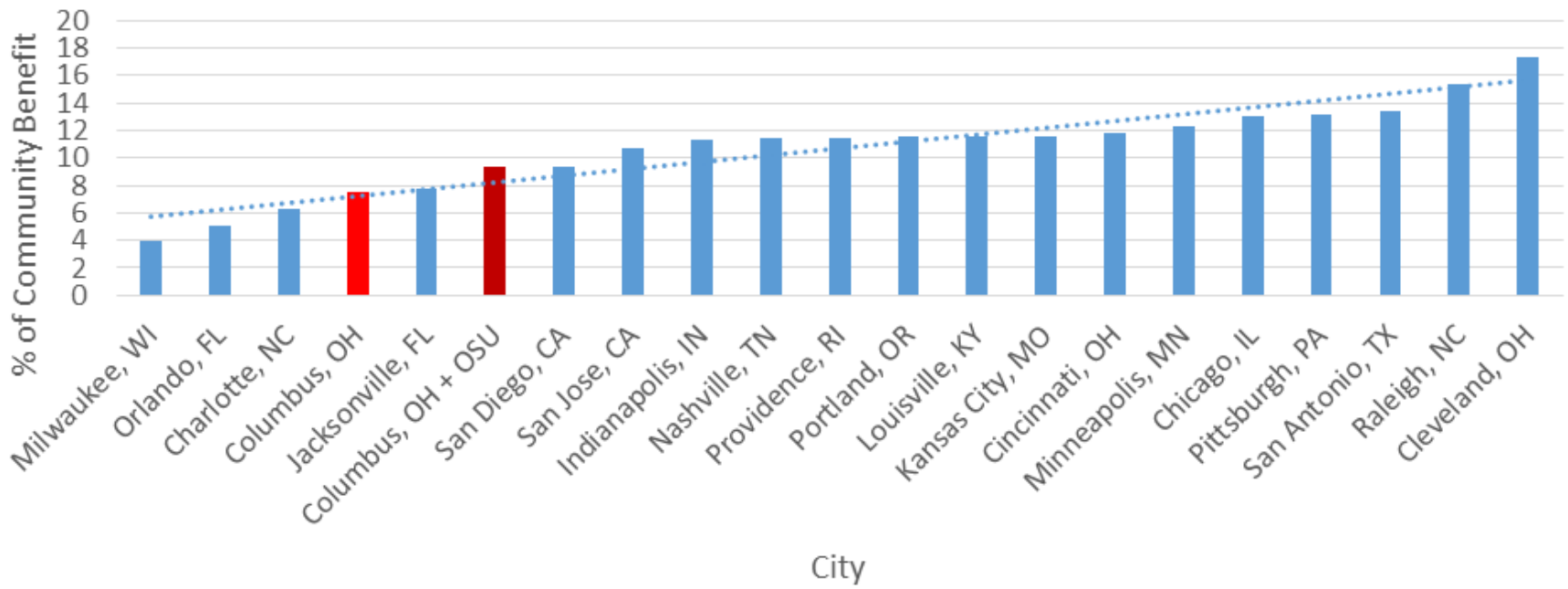

Figure 2. Percentage of Averaged City's Nonprofit Hospital(s) Total Community Benefit to Averaged Total Expenses

benefit with 10 cities between approximately $50 \%$ to $70 \%$. See Figure 3.

It is believed by the COHC that the total expense of charity care in central Ohio is equally distributed across all hospitals systems due to its shared charity care thresholds. Charity care dollars to total expenses at each institution is $1.36 \%$ The Ohio State University Wexner Medical Center, 4.50\% Nationwide Children's Hospital, 6\% Mount Carmel, and 7\% OhioHealth. Despite The Ohio State University Wexner Medical Center reporting a lower percentage of charity care to total expenses, they do provide similar levels of total community benefit to total expenses with each institution reporting 9.12\% The Ohio State University Wexner Medical Center, $11.32 \%$ Nationwide Children's Hospital, 7\% Mount Carmel, and $9 \%$ OhioHealth. See Figure 4.

\section{DISCUSSION}

The purpose of this research was to determine if hospitals in peer cities to Columbus, Ohio, provided similar levels of community benefit. From the data used for this analysis, only Columbus, Ohio and Providence, Rhode Island, have a common income threshold

\section{$\%$ of Charity Care of Total Community Benefit}

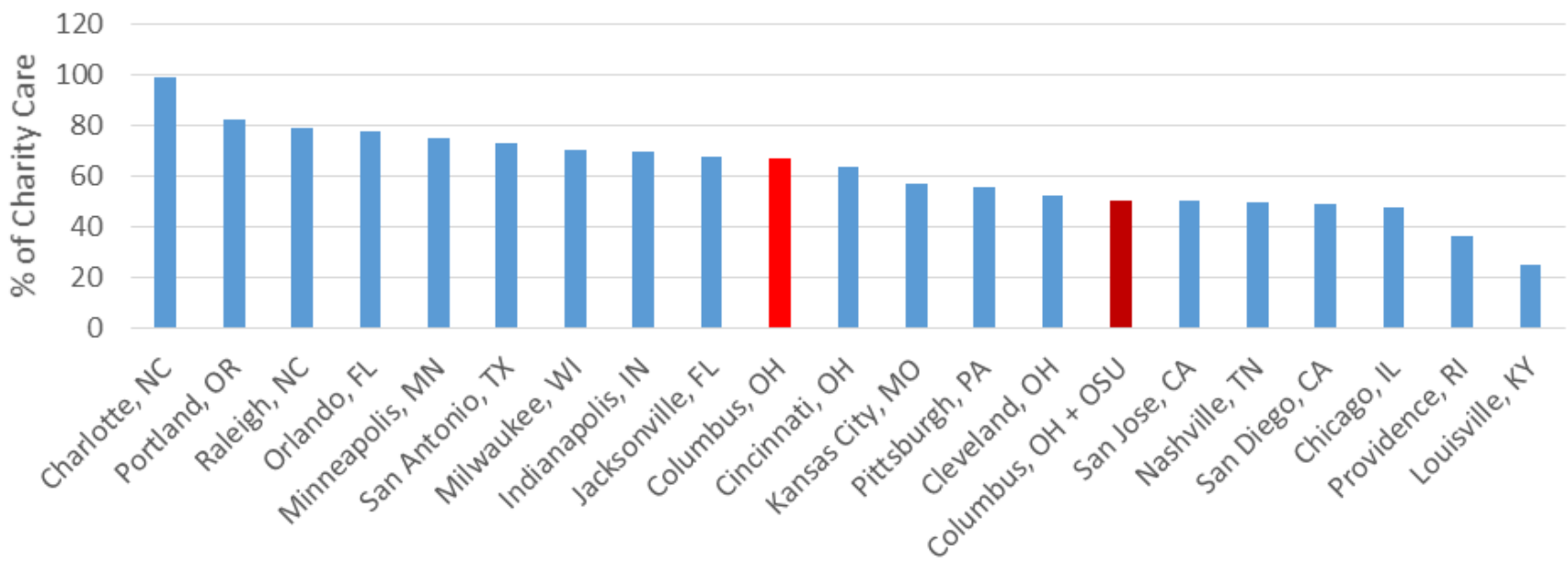

City 
(percentage of federal poverty guidelines) for free and discounted care across all hospital systems in their metro area. There is a collaboration between Central Ohio hospitals to have the same income thresholds to determine charity care, however, it is unknown if a similar collaboration exists in Providence. Common charity care thresholds ensure that one hospital system is not being utilized more than another due to its charity care policies. The amount of charity care provided by a hospital will also depend largely on the location of the hospital and ease of access to those that would qualify for charity care. There did appear to be a trend or grouping of common policies between hospital systems, for example in Cincinnati and Chicago, but not for all hospitals across the board. The data demonstrate that Columbus does provide less overall community benefit in regard to total expenses compared to peer cities; however, this appears to be only true regarding other community benefits apart from charity care. Columbus was near the median in regard to percentage of charity care to total community benefit. Despite Columbus being on the lower end of the percentage of community benefit provided compared to other peer cities, Columbus, at $7.57 \%$, is near the average of a study of 1800 United States nonprofit hospitals who reported an average of community benefit of 7.5\%. ${ }^{7}$ When The Ohio State University Wexner Medical Center was factored into the Columbus analysis, they provided a slightly higher percentage of total community benefit to total expenses.
This work may be lacking a complete data set in capturing the entire story of community benefit due to government run hospitals not included in the data analysis, except for The Ohio State University Wexner Medical Center. Subsequently, the average community benefit and charity care values reported in this research might not capture the entire community benefit of a city. However, this information is thought to be the first research regarding hospital's specific community benefit. This information is helpful to not only the hospitals and the communities they serve, but also helpful to federal and state government to monitor if nonprofit hospitals are performing the way they should to deserve tax-exempt status.

Results of 1 study indicated hospitals that reported community benefit allocated less than $8 \%$ of all community benefit expenditures to community health improvement with most of the funds utilized for charity care, health professional training, Medicaid costs, and research. ${ }^{9}$ This is a concern given the financial benefit hospitals are accruing from their tax-exempt status, which across all states was estimated at $\$ 12.6$ billion in 2002 and $\$ 24.6$ billion in $2011 .^{9}$ A recent study reported that there is high variability across nonprofit hospitals regarding community benefit. This study found that $62 \%$ of nonprofits provided community benefits greater than the tax benefits they received; however, if only charity care is factored in then only $20 \%$ of the nonprofit hospitals in the study exceed the value of their tax exemption. 6 These studies

\section{Columbus, Ohio, Nonprofit Hospitals}

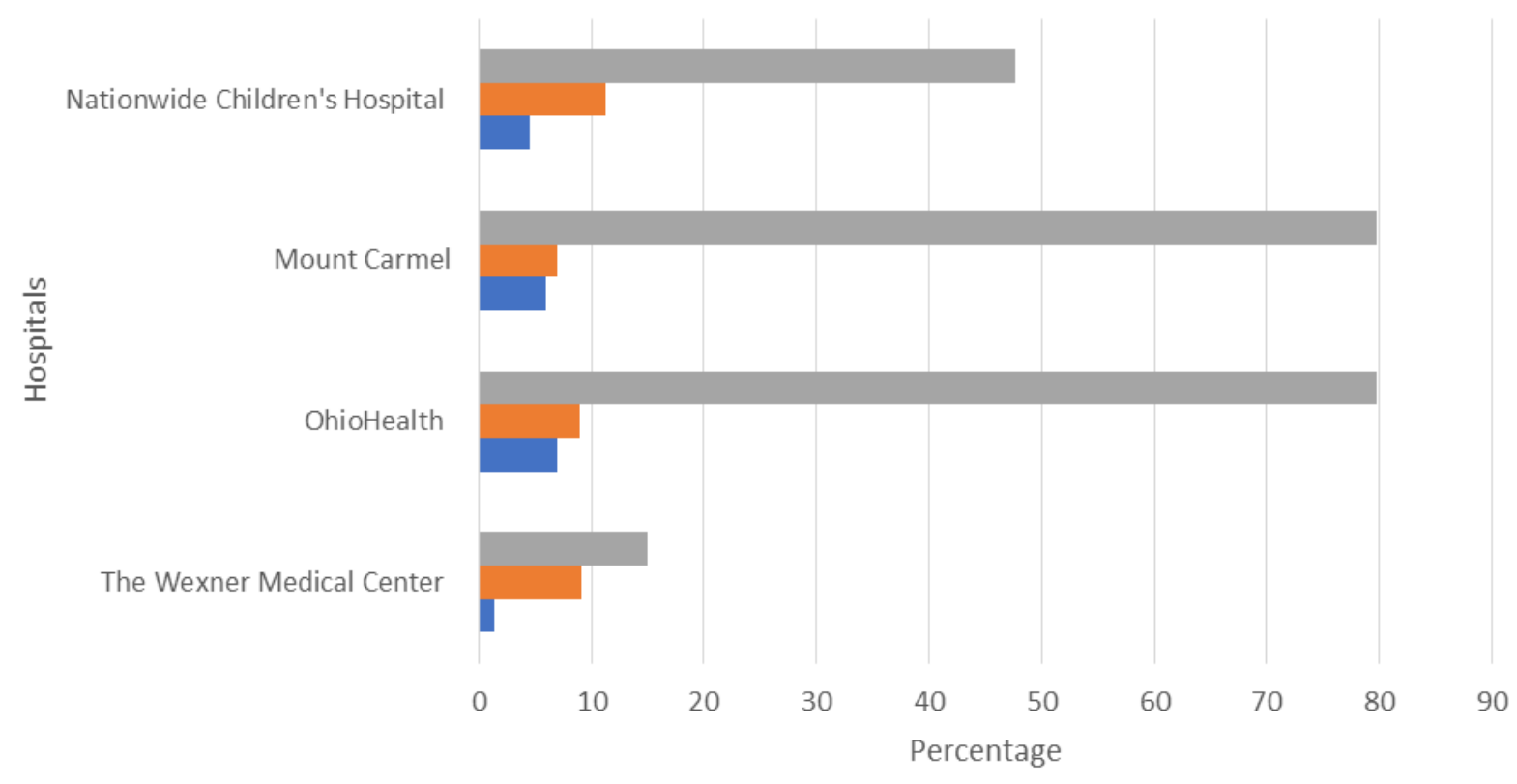

" \% of Charity Care to Total Community Benefit $\square \%$ of Total benefits to Total Expenses

- \% of Charity Care to Total Exepnses

\section{Figure 4. Community Benefit Data for the Central Ohio Hospitals}


suggest that many nonprofit hospitals benefit greatly from their tax-exempt status yet provide minimal community benefits.6,9,16 This demonstrates a lack in regulation regarding nonprofit hospitals use of community benefit. By researching community benefit and how Central Ohio hospitals stack up to their peer cities, it is evident there is a lack in government regulation of community benefit nationally. Of those states who have adopted some type of community benefit regulation, they were consistently associated with higher levels of hospital-provided community benefits. A 2018 article suggests that state regulatory intensity conveys a strong signal to community hospitals that more spending is expected. ${ }^{5}$ This proposes that federal regulation would most likely have the same effect.

Since 1969, hospitals have been required to provide services to the communities they serve in exchange for tax exemption and over time this has become known as community benefit, which includes charity care through financial assistance programs. ${ }^{17}$ Nonprofit hospitals also supplement shortfalls for coverage in Medicaid patients. ${ }^{11}$ Compared to the national average, Ohio has a similar uninsured population at approximately 8.5\% in 2018.18 This factor would impact the amount of charity care Central Ohio's hospitals provide to total expenses as well as the amount of charity care provided for the peer cities uninsured population. Another factor that would determine the amount of charity care provided is whether hospitals are located in a state with Medicaid expansion, like Ohio, due to The Patient Protection and Affordable Care Act. Therefore, Central Ohio hospitals may not provide as much charity care as other cities whose states did not expand Medicaid. Central Ohio's nonprofit hospitals have agreed on the same charity care policies, which is unique compared to other communities across the county. The amount of charity care provided in the Columbus area may have an effect on the total resources available for other community benefits. Historically research shows that the $85 \%$ of community benefit funds is spent on charity care and uncompensated clinical care, consequently leaving minimal funds for community health activities. ${ }^{8}$ This leaves a major problem for funding for other community benefits which have been shown to make an impact on the communities in which they serve.

A review of nonprofit hospital community benefit in the United States from 2010 to 2019 found a limited role of hospital leadership related to community benefit. This lack of leadership could cause disorganization and misuse of community benefit funds. Results of a survey conducted in 2011 found that hospital governing boards did not engage in community benefit planning and only $36 \%$ of the systems surveyed had assigned responsibility to manage and execute community benefit. ${ }^{7}$ This same survey also reviewed community needs assessments which are now required of hospitals by the IRS every 3 years to maintain their tax-exempt status. In 2013, few hospitals studied had a broad spectrum of community members in the community needs assessment process. Ironically, the hospitals in communities with the lowest needs based on county health rankings were more likely to com- plete community health needs assessment activities versus those with the greatest health need. There was also found to be poor collaboration between nonprofit hospitals and public health departments with approximately $50 \%$ of collaboration demonstrated between entities. ${ }^{7}$

Efforts to improve hospital community benefit and health have been shown to include high quality collaboration between all stakeholders, including consultants. Prior research has shown hospitals reporting high levels of community health needs assessment implementation, including the creation of community health programming, spent more on community improvement versus those who did not implement changes following a community needs assessment. ${ }^{7}$ This demonstrates the need for IRS policy change to enforce and monitor hospital community health needs assessment implementation, the development of strategies for improvement, and provide incentives for change. While community benefit has been researched there is minimal examination of the current data including specific values or what type of community benefit is actually being provided to the community other than charity care. One possible solution would be increased transparency of data with the development of an online database to access hospital's community benefit activities. Another solution would be the development of clear expectations and enforcing accountability, which could be set at a federal or state level. There have been reports of a race to the bottom effect with setting specific hospital spending guidelines, but this could be offset by not providing specific standards in regard to financial costs but in terms of expected community health outcomes as a result of hospital community benefit spending. ${ }^{13}$ From this research it is evident there is a significant need for policy change and data transparency for community benefit to truly have an impact on population and community health.

\section{Limitations}

There are some limitations to this study. The latest tax year that could be obtained for all hospitals was from 2018; therefore, there is most likely variation in data as this is only capturing 1 year of tax reporting. In addition, government hospitals are not required to submit an IRS Tax Form 990, Schedule H; therefore, all government hospitals, including Veterans Health Administrations, were excluded from this research, except The Ohio State University Wexner Medical Center whose data was supplied by the COHC. Not reflected in this article are inherent state differences in health policy. Varying levels of community benefit policy per state could contribute to overall differences across health care systems when comparing Columbus to its peer cities. Lastly, 12 of the 20 hospitals did not report a percentage for the federal poverty guideline in factoring eligibility for free and/or discounted care, but reported a number in the tens of thousands. No reference value or definition could be located from the IRS or a literature review, however it is suspected that number is reported as income level versus percentage of the federal poverty guideline. For data analysis, 
hospitals and hospital systems that reported a dollar amount for federal poverty level, the number was converted to a percentage of the federal poverty guideline by the 2021 poverty guidelines for the 48 contiguous states and the District of Columbia published via the United States Department of Health and Human Services. ${ }^{19}$

\section{PUBLIC HEALTH IMPLICATIONS}

Using Columbus, Ohio, as a focal point for data collection it is clear that there is variability in the amount and type of community benefit nonprofit hospitals provide. Central Ohio hospitals provide the same charity care thresholds and appear to provide similar total community benefit dollars across hospital systems; however, the hospitals do not directly report how funds are being used and have no legal obligation to do so. Current federal regulations and standards do not assess whether the community benefits reported are affecting community health outcomes. A higher standard of community benefit reporting and implementation needs to be enforced including the use of outcome measures and specific population health information, like improved community access to health services, overall enhanced health of the community, and increased community medical knowledge, to have an effect on community health outcomes. These standards should include desired community health outcomes, like those mentioned above, rather than specific community benefit financial spending requirements and guidelines to avoid a race to the bottom effect on community benefit. Hospital community benefit should target the greatest need in a community, directly linking public health issues of a community such as health disparities and serving underserved populations.

\section{ACKNOWLEDGMENTS}

This descriptive research was compiled for the Central Ohio Hospital Council (COHC). The authors thank the Central Ohio Hospital Council as well as The Ohio State University College of Public Health faculty for their guidance and expertise in this work

\section{REFERENCES}

1. Rosen, G. The Structure of American Medical Practice 1875-1941. Philadelphia: University of Pennsylvania Press; 1983.

2. Starr P. The Social Transformation of American Medicine. Cambridge, MA: Basic Books. 1982

3. CMS's program history. Centers for Medicare and Medicaid Services. Accessed November 26, 2021. https://cms.gov/About-CMS/Agency-Information/History

4. American Hospital Association. AHA Guide to the Health Care Field. Chicago, Il: Health Forum. LLC; 2019.

5. Singh SR, Young GJ, Loomer L, Madison K. State-level community benefit regulation and nonprofit hospitals' provision of community benefits. J Health Polit Policy Law. 2018;43(2):229-269. https://doi.org/10.1215/03616878-4303516

6. Herring B, Gaskin D, Zare H, Anderson G. Comparing the value of nonprofit hospitals' tax exemption to their community benefits. Inquiry. 2018;55:46958017751970. https://doi.org/10.1177/0046958017751970
7. Rozier MD. Nonprofit hospital community benefit in the U.S.: a scoping review from 2010 to 2019. Front Public Health. 2020;8:72. Published March 11, 2020.

https://doi.org/10.3389/fpubh.2020.00072

8. Evashwick CJ, Jackson P. The evolution of community benefit: perspective on progress toward purpose. Front Public Health. 2020;8:27. Published March 2, 2020. https://doi.org/10.3389/fpubh.2020.00027

9. Rosenbaum S, Kindig DA, Bao J, Byrnes MK, O'Laughlin C. The value of the nonprofit hospital tax exemption was $\$ 24.6$ billion in 2011. Health Aff (Millwood). 2015;34(7):1225-1233. https://doi.org/10.1377/hlthaff.2014.1424

10. Goodman CW, Flanigan A, Probst JC, Brett AS. Charity care characteristics and expenditures among US tax-exempt hospitals in 2016. Am J Public Health. 2020;110(4):492-498. https://doi.org/10.2105/AJPH.2019.305522

11. GuideStar. Candid. Updated 2021. Accessed March 25, 2021. https://guidestar.org/

12. Rubin DB, Singh SR, Young GJ. Tax-exempt hospitals and community benefit: new directions in policy and practice. Annu Rev Public Health. 2015;36:545-557. https://doi.org/10.1146/annurev-publhealth-031914-122357

13. About Us. Central Ohio Hospital Council. Accessed March 21, 2021. https://centralohiohospitals.org/about/

14. Instructions for Schedule H (Form 990) 2020. Internal Revenue Service. Updated 2021. Accessed March 25, 2021.

https://irs.gov/instructions/i990sh

15. Benchmarking Central Ohio. The Columbus Foundation. Updated 2016. Accessed February 25, 2021.

https://columbusfoundation.org/umbraco-media/2933/ report_benchmarking-central-ohio-2016.pdf

16. Young GJ, Chou CH, Alexander J, Lee SY, Raver E. Provision of community benefits by tax-exempt U.S. hospitals. $N$ Engl J Med. 2013;368 (16):1519-1527. https://doi.org/10.1056/NEJMsa1210239

17. Singh SR, Sinay T, Jackson P, Evashwick CJ. Editorial: Hospitals' benefit to the community: research, policy and evaluation. Front Public Health. 2020;8:353 https://doi.org/10.3389/fpubh.2020.00353

18. Measuring the nation's social and economic well-being. United States Census Bureau. Updated 2019. Accessed February 15, 2021. https://census.gov/library/visualizations/2019/comm/wellbeing.html?cid=well-being

19. The 2021 poverty guidelines. Federal Register by the U.S. Department of Health and Human Services. The U.S. Department of Health and Human Services. Updated 2021. Accessed March 28, 2021. https://aspe.hhs.gov/2021-poverty-guidelines 